\title{
EFEITO DA COBERTURA NAS PERDAS DE SOLO EM UM ARGISSOLO VERMELHO- AMARELO UTILIZANDO SIMULADOR DE CHUVA ${ }^{1}$
}

\author{
DEMÉTRIUS D. SILVA ${ }^{2}$, FERNANDO F. PRUSKI ${ }^{3}$, CARLOS E. G. R. SCHAEFER ${ }^{4}$, \\ RICARDO S. S. AMORIM ${ }^{5}$, KARLOS W. N. PAIVA ${ }^{6}$
}

RESUMO: O objetivo deste trabalho foi avaliar o efeito da porcentagem de cobertura do solo e da energia cinética decorrente de chuvas simuladas sobre as perdas de solo. $\mathrm{O}$ experimento consistiu de seis parcelas experimentais $\left(4 \mathrm{~m}^{2}\right)$, as quais foram mantidas com coberturas de $0 ; 20 ; 40 ; 60 ; 80$ e $100 \%$, utilizando manta de Bidin, simulando condição de manejo de cultivo em contorno. Utilizou-se de simulador de chuva sobre Argissolo Vermelho-Amarelo, com declividade média de 9,5\%. Foram utilizadas as intensidades de precipitação de 60;80;100 e $120 \mathrm{~mm} \mathrm{~h}^{-1}$, associadas às durações de 68 ; 40; 24 e 14 minutos, resultando nos valores de energia cinética de $1.401 ; 1.122 ; 841$ e $589 \mathrm{~J} \mathrm{~m}^{-2}$, respectivamente. Para cada uma das intensidades de precipitação, realizaram-se seis aplicações sucessivas, espaçadas de $12 \mathrm{~h}$. Verificou-se diminuição acentuada nas perdas de solo com o aumento da porcentagem de cobertura do solo e que os maiores valores de perda de solo foram obtidos para as menores intensidades de precipitação, em virtude da maior duração da precipitação. Observou-se, também, que a cobertura do solo apresentou maior influência do que a intensidade de precipitação nas perdas de solo e que o potencial erosivo das chuvas intensas foi reduzido pelo aumento da cobertura do solo, passando o processo de erosão a ser dominado pelo efeito erosivo do escoamento superficial, o qual ocorre por maior período nas chuvas menos intensas, por apresentarem maior duração.

PALAVRAS-CHAVE: erosão hídrica, intensidade de precipitação, cobertura do solo.

\section{EFFECT OF THE COVER ON SOIL LOSSES IN A RED-YELLOW PODZOLIC SOIL UNDER SIMULATED RAINFALL}

\begin{abstract}
The present work was carried out in the experimental area of the Agronomy Department of the Viçosa Federal University, Brazil, aiming to evaluate the effect of soil cover and kinetic energy of rainfall on soil losses. The soil management used was the contour cropping, with six experimental units $\left(4,0 \mathrm{~m}^{2}\right)$ with soil cover percentage of $0 ; 20 ; 40 ; 60 ; 80$ and $100 \%$. The tests were conducted with a rotative rainfall simulator and the soil in the experimental area was a Red-Yellow Podzolic, with an average slope of $9.5 \%$. The six rainfall intensities used were $60 ; 80 ; 100$ and 120 $\mathrm{mm} \mathrm{h}^{-1}$, with periods of time of 68; 40;24 e 14 minutes, and resulting in kinetic energy values of 1,$401 ; 1,122 ; 841$; e $589 \mathrm{~J} \mathrm{~m}^{-2}$, respectively. Six successive rainfall applications were made in 12 hour periods, regularly, for each rainfall intensity. It was observed a pronounced decrease in soil losses with higher soil cover percentage, and higher soil losses with lower rainfall intensities, due to the long rainfall period of application. The influence of soil cover on soil loss was more effective than rainfall intensity and that, the erosive potential of the intense rains was reduced by soil cover increase, passing the erosion process to be dominated by erosive effect of the runoff, which occurs for a larger period in the less intense rains, due to their larger duration.
\end{abstract}

KEYWORDS: water erosion, rainfall intensity, soil cover.

\footnotetext{
${ }^{1}$ Trabalho financiado pela FAPEMIG.

${ }^{2}$ Prof. Adjunto, D.Sc., Depto. de Engenharia Agrícola, UFV, Viçosa - MG, Fone: (0XX31)3891-1904, david@ufv.br. Bolsista CNPq.

${ }^{3}$ Prof. Titular, D.Sc., Depto. de Engenharia Agrícola, UFV, Viçosa - MG, ffpruski@ufv.br. Bolsista CNPq.

${ }^{3}$ Prof. Adjunto, Ph.D., Depto. de Solos, UFV, Viçosa - MG, carlos.schaeffer@ solos.ufv.br. Bolsista CNPq.

${ }^{4}$ Engoㅡㄹ. Agrônomo, D.Sc, Pesquisador, UFMT, rsamorim@cpd.ufmt.br.

${ }^{5}$ Eng ${ }^{0}$ Agrônomo, M.Sc., Depto. de Engenharia Agrícola, UFV, Viçosa - MG, kwelby@alunos.ufv.br

Recebido pelo Conselho Editorial em: 28-1-2003

Aprovado pelo Conselho Editorial em: 20-6-2005
} 


\section{INTRODUÇÃO}

No Brasil, a principal forma de erosão é a hídrica, que é provocada pela ação das chuvas, acarretando a desagregação e o transporte do solo pela enxurrada. Além das partículas de solo em suspensão, o escoamento superficial transporta nutrientes, matéria orgânica, sementes e defensivos agrícolas, acarretando o empobrecimento gradativo dos solos agrícolas, a elevação do custo de produção e, às vezes, resultando no abandono de áreas anteriormente produtivas (BERTONI \& LOMBARDI NETO, 1990; PARKER et al., 1995).

FOSTER (1982) divide o processo erosivo em duas fases. A primeira é a desagregação do solo superficial pelo impacto das gotas de chuva ou pelo escoamento superficial, e a segunda é o transporte das partículas de solo desagregadas pelo escoamento superficial, desde o ponto em que sofrem o desprendimento, até um local do declive onde a deposição ocorre devido à carga de sedimentos no escoamento superficial exceder a sua capacidade de transporte. Segundo OWOPUTI \& STOLTE (1995), a desagregação do solo é causada por forças aplicadas sobre as partículas do solo por agentes que são, principalmente, as gotas de chuva e o escoamento superficial, e a predominância de um ou de outro fator no desprendimento e transporte dos sedimentos depende da forma como ocorre a erosão (entressulcos ou em sulco).

Nas áreas onde ocorre a erosão laminar (entressulcos), em que a energia de impacto das gotas de chuva é fundamental no processo de desagregação e, também, para o transporte de partículas pelo escoamento laminar, os resíduos vegetais na superfície podem reduzir consideravelmente a erosão hídrica. WILDNER (1985), analisando o efeito dos resíduos dispostos na superfície do solo, observou que as perdas de solo e água foram menores nos tratamentos com resíduos na superfície. Segundo o autor, a proteção proporcionada ao solo pelos resíduos impede que as gotas de chuva atinjam diretamente o solo, evitando, desse modo, a desagregação de suas partículas. Com os agregados protegidos, maiores taxas de infiltração podem ser mantidas ao longo do período da chuva. Além disso, os resíduos em superfície retêm por mais tempo a água de escoamento, aumentando a lâmina de água infiltrada no solo e diminuindo a velocidade e, conseqüentemente, a capacidade de transporte do escoamento superficial.

Segundo YOUNG \& WIERSMA (1973), redução de 90\% na energia cinética das gotas incidentes sobre a superfície do solo, mantendo-se a taxa de aplicação de água constante, pode reduzir a perda de solo em até 90\%. BRAIDA (1994), utilizando simulador de chuva em um Argissolo Vermelho-Escuro, observou que a erosão entressulcos decresceu exponencialmente com o aumento da cobertura do solo por resíduos vegetais. As parcelas com cerca de $100 \%$ de cobertura apresentaram redução de $92 \%$ na erosão entressulcos em relação ao solo descoberto.

Nesse contexto, o presente trabalho teve como objetivos analisar o efeito da porcentagem de cobertura do solo e da energia cinética decorrente de chuvas simuladas sobre as perdas de solo entressulcos e ajustar modelos de regressão que correlacionem as perdas de solo com a energia cinética acumulada incidente sobre o solo.

\section{MATERIAL E MÉTODOS}

O presente trabalho foi conduzido na área experimental do Departamento de Fitotecnia da Universidade Federal de Viçosa, em Viçosa - MG. A realização dos ensaios foi feita com a utilização de simulador de chuvas de braços rotativos equipado com bocais VeeJet 80.100, conforme o modelo da Universidade de Nebraska - USA (SWANSON, 1965), o qual é constituído de plataforma móvel, motor estacionário de dois tempos com $5,9 \mathrm{~kW}(8 \mathrm{cv})$, eixo vertical e dez tubos dispostos radialmente. Foram utilizados 20 bocais, distribuídos alternadamente em forma de espirais concêntricas opostas, para obter as intensidades de precipitação desejadas. 
Foram realizados testes preliminares com o simulador de chuvas para a verificação da uniformidade de distribuição de água, permitindo, assim, a identificação de áreas com precipitação uniforme para a locação das parcelas experimentais. A calibração do simulador de chuvas foi feita por meio da medição da intensidade de precipitação, obtida por coletores de chuva uniformemente espaçados na área experimental, correspondente a diversos valores de pressões de trabalho. Para selecionar definitivamente o local de instalação das seis parcelas experimentais, foram avaliadas, durante a calibração, a intensidade de precipitação e a uniformidade de distribuição de água em cada uma das possíveis parcelas, de forma que a intensidade de precipitação fosse a mesma em todas as parcelas e que o coeficiente de uniformidade de aplicação fosse superior a 80\%. Foram escolhidas as seis disposições que apresentaram os maiores coeficientes de uniformidade para as intensidades de precipitação a serem aplicadas.

Sabendo-se que a condição crítica para a ocorrência de escoamento superficial é aquela em que o solo se encontra saturado (antes da incidência da chuva de projeto), aplicou-se, antes do início dos testes, lâmina d'água de $100 \mathrm{~mm}$ no solo pelo simulador de chuvas. Para evitar a formação de selamento superficial decorrente dessa precipitação, toda a superfície do solo das parcelas experimentais foi coberta por uma manta sintética de alta permeabilidade (Bidim).

O solo da área experimental foi classificado como Argissolo Vermelho-Amarelo, do qual se retiraram amostras para a caracterização física do perfil do solo. Na Tabela 1, são apresentados os resultados da análise textural das amostras retiradas da área onde foram realizados os testes. O preparo do solo consistiu de uma aração à profundidade de cerca de $25 \mathrm{~cm}$ com arado de discos, uma gradagem (grade de discos) e, para a uniformização do terreno, utilizou-se da enxada rotativa.

TABELA 1. Características físicas do perfil do solo da área experimental.

\begin{tabular}{|c|c|c|c|c|c|c|c|}
\hline \multirow{2}{*}{ Horizonte } & Profundidade & Argila & $\mathrm{ADA}^{1}$ & Areia Fina & Areia Grossa & Silte & \multirow{2}{*}{ Classe Textura } \\
\hline & $\mathrm{cm}$ & & & $-\%$ & & & \\
\hline Ap & 0 a 10 & 37 & 24 & 17 & 27 & 19 & Argilo-arenoso \\
\hline $\mathrm{AB}$ & 10 a 20 & 38 & 22 & 14 & 28 & 20 & Franco-arenoso \\
\hline $\mathrm{Bt}_{1}$ & 20 a 40 & 45 & 36 & 14 & 26 & 15 & argiloso \\
\hline $\mathrm{Bt}_{2}$ & 40 a 60 & 45 & 32 & 13 & 24 & 18 & argiloso \\
\hline $\mathrm{BC}$ & 60 a 140 & 50 & 40 & 12 & 19 & 19 & argiloso \\
\hline $\mathrm{C}$ & $>140$ & 60 & 45 & 11 & 19 & 10 & Muito argiloso \\
\hline
\end{tabular}

1 - argila dispersa em água.

O experimento constou, para a condição de manejo do solo estabelecida (preparo do solo e cultivo em contorno, acompanhando as curvas de nível do terreno), de seis parcelas experimentais, com 0; 20; 40; 60; 80 e 100\% de cobertura do solo e com declividade média de 9,5\% (Figura 1), as quais foram distribuídas de forma casualizada sob a área útil do simulador de chuva em locais que apresentavam mesma intensidade de precipitação e elevado coeficiente de uniformidade (superior a $80 \%$ ). Foram feitas quatro baterias de testes correspondentes às intensidades de precipitação de 60; 80; $100 \mathrm{e} 120 \mathrm{~mm} \mathrm{~h}^{-1}$, associadas às durações de 68; 40; 24 e 14 minutos, respectivamente. Tais combinações foram obtidas a partir da relação entre intensidade-duração-freqüência da precipitação (para um período de retorno de 10 anos) determinada por PINTO (1995) para a cidade de Viçosa MG.

A cobertura da superfície do solo foi feita com manta sintética de alta permeabilidade (Bidim OP 30), com o objetivo de absorver a energia cinética das gotas d'água, simulando a cobertura do solo pelas culturas, na linha de plantio, conforme representado na Figura 1. As parcelas experimentais possuíam área de $4,0 \mathrm{~m}^{2}$ e as fileiras de plantio, substituídas neste experimento pelo Bidim, foram espaçadas de $0,5 \mathrm{~m}$. 


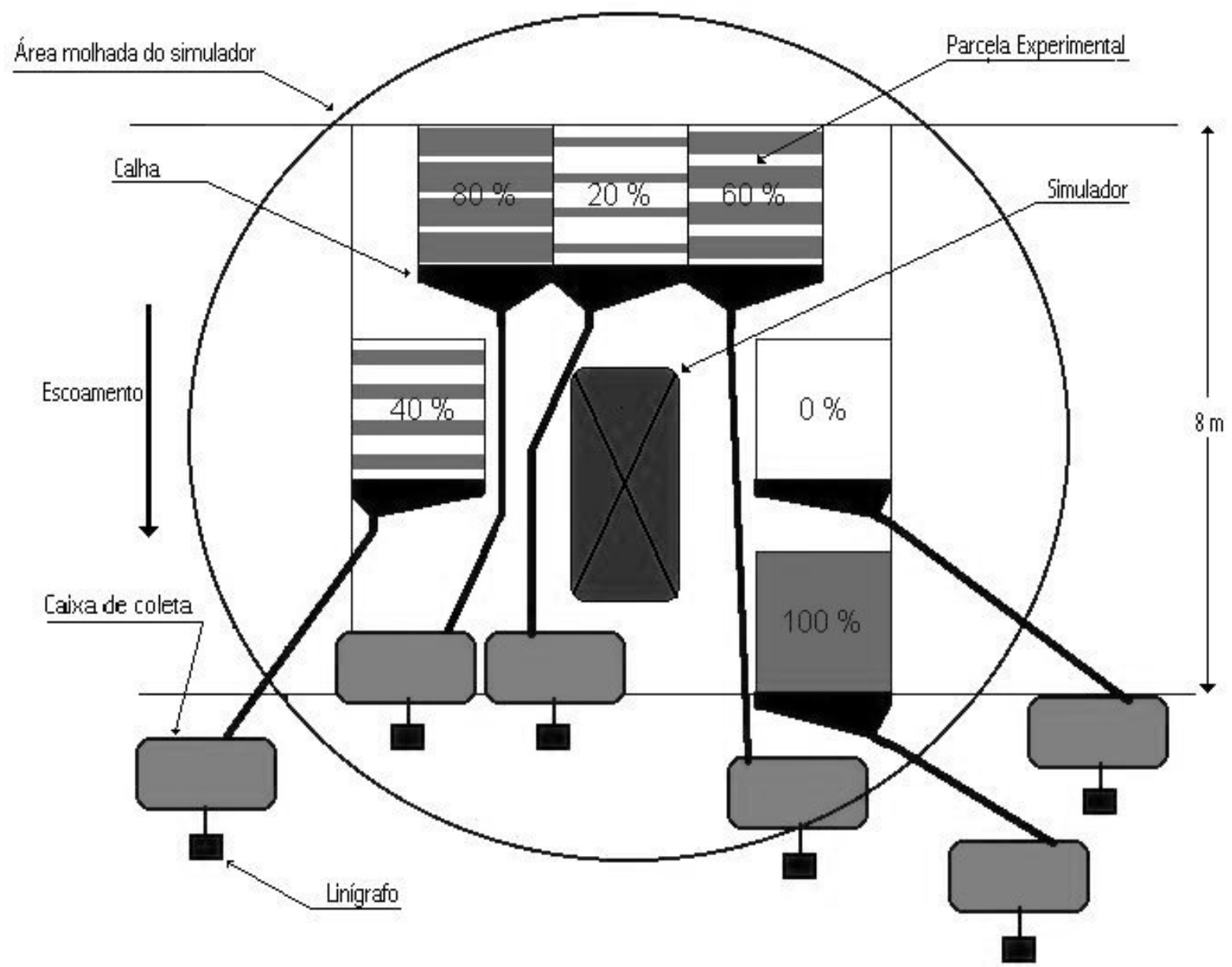

FIGURA 1. Esquema do experimento para a determinação do escoamento superficial e perdas de solo.

A determinação da energia cinética das precipitações aplicadas pelo simulador de chuvas de braços rotativos foi feita pelas eqs.(1) e (2), propostas por WISCHMEIER \& SMITH (1958).

$$
\begin{array}{ll}
\mathrm{Ec}=(17,124+5,229 \log \mathrm{I}) \mathrm{L}_{\mathrm{t}} & \text { para I }<76 \mathrm{~mm} \mathrm{~h}^{-1} \\
\mathrm{Ec}=(17,124+5,229 \log 76) \mathrm{L}_{\mathrm{t}} & \text { para I } \geq 76 \mathrm{~mm} \mathrm{~h}^{-1}
\end{array}
$$

em que,

Ec - energia cinética da chuva natural, $\mathrm{J} \mathrm{m}^{-2}$

I - intensidade de precipitação, $\mathrm{mm} \mathrm{h}^{-1}$, e

$\mathrm{L}_{\mathrm{t}}$ - lâmina total precipitada, $\mathrm{mm}$.

Para fins de conversão da energia cinética da chuva natural para chuva simulada, foi utilizado um coeficiente redutor igual a 0,78, conforme recomendado por YOUNG \& BURWELL (1972).

Durante os testes correspondentes a cada uma das quatro intensidades de precipitação adotadas, foram feitas seis aplicações sucessivas, espaçadas por 12 horas, a fim de caracterizar a evolução das perdas de solo em função da lâmina total aplicada.

Inicialmente, foram realizados os testes para a intensidade de precipitação de $60 \mathrm{~mm} \mathrm{~h}^{-1}$. Após as seis aplicações sucessivas, retirou-se o simulador, desmontaram-se as parcelas e realizou-se novo preparo do solo, conforme descrito anteriormente. Em seguida, montaram-se novamente as parcelas 
experimentais no mesmo local, realizando as aplicações referentes à intensidade de precipitação de $80 \mathrm{~mm} \mathrm{~h}^{-1}$. O mesmo procedimento foi usado para as demais intensidades de precipitação.

As perdas de solo foram determinadas pelo método direto (BERTONI \& LOMBARDI NETO, 1990), por meio da coleta do solo transportado por arrastamento superficial nas caixas de cada parcela experimental. Em cada caixa de coleta, foi instalada armação de madeira com tela perfurada, sobre a qual se colocou manta de Bidim para possibilitar a coleta das partículas de solo transportadas após cada uma das aplicações. É importante ressaltar que a quantidade de solo em suspensão que passava pelos poros da manta de Bidim, juntamente com o escoamento, foi considerada inexpressiva frente ao material retido pela mesma. $\mathrm{O}$ solo coletado foi levado à estufa $\left(105^{\circ} \mathrm{C}\right.$ por $\left.24 \mathrm{~h}\right)$ e posteriormente determinado o seu peso após a secagem.

Foram realizadas análises de regressão, por intermédio do programa estatístico "SAEG" (RIBEIRO, 2001), desenvolvido pela Universidade Federal de Viçosa, com o objetivo de obter equações de ajuste, tendo como variável dependente a perda de solo e, independentes, a porcentagem de cobertura do solo e a energia cinética decorrente das sucessivas aplicações.

\section{RESULTADOS E DISCUSSÃO}

$\mathrm{Na}$ Tabela 2, são apresentados os valores de perdas de solo $\left(\mathrm{Mg} \mathrm{ha}^{-1}\right)$ e de água $(\mathrm{mm})$ para cada evento de precipitação, em função da energia cinética total decorrente das precipitações e da porcentagem de cobertura do solo, para as intensidades de 60; 80; 100 e $120 \mathrm{~mm} \mathrm{~h}^{-1}$, respectivamente.

Os resultados referentes à parcela com $60 \%$ de cobertura do solo foram descartados, pois essa apresentou problemas em todas as intensidades de precipitação avaliadas, gerando resultados discrepantes, devido, provavelmente, à variabilidade espacial na área, tendo em vista que esse comportamento não foi observado para nenhuma das demais parcelas experimentais.

Para as diversas intensidades de precipitação adotadas, verifica-se que a parcela com 100\% de cobertura não apresentou perdas de solo. Isso pode ser explicado pela proteção proporcionada com a completa cobertura do solo, evitando, dessa forma, a desagregação provocada pelo impacto das gotas de chuva e a formação do selamento superficial, favorecendo, conseqüentemente, a infiltração da água no solo e a redução do escoamento superficial. MANNERING \& MEYER (1963) verificaram que tratamentos com 87; 98 e 100\% de cobertura do solo com palha de trigo eliminaram completamente o escoamento e controlaram a erosão até o quarto teste de chuvas simuladas.

Observa-se, na Tabela 2, que as perdas de solo e de água diminuíram com o aumento da porcentagem de cobertura do solo, ocorrendo as maiores perdas de água e solo nas parcelas sem cobertura do solo. Elevando-se a porcentagem de cobertura de 0 para $80 \%$, verificou-se redução, em média, de $99,5 \% ; 85,5 \% ; 76,5 \%$ e $87,1 \%$ nas perdas de solo e de $68,8 \% ; 78,7 \% ; 61,5 \%$ e $83,6 \%$ nas perdas de água para as intensidades de $60 ; 80 ; 100$ e $120 \mathrm{~mm} \mathrm{~h}^{-1}$, respectivamente. A utilização de apenas $20 \%$ de cobertura resultou em redução de $48,8 \% ; 35,5 \% ; 51,1 \%$ e $81,3 \%$ nas perdas de solo e de $11,4 \% ; 38,6 \% ; 15,7 \%$ e $56,5 \%$ nas perdas de água em relação à parcela sem cobertura. Esses resultados mostram que a cobertura do solo reduz de forma mais eficiente as perdas de solo quando comparada à redução nas perdas de água, corroborando as observações feitas por HERNANI et al. (1997). 
TABELA 2. Perdas totais de solo (PS) e de água (PA) em função da energia cinética total da precipitação (Ec) e da porcentagem de cobertura do solo (\%), para as diversas intensidades de precipitação (Ip) adotadas.

\begin{tabular}{|c|c|c|c|c|c|c|c|c|c|c|c|c|c|c|}
\hline \multirow{3}{*}{$\begin{array}{c}\mathrm{Ip} \\
\mathrm{mm} \mathrm{h}^{-1}\end{array}$} & \multirow{3}{*}{$\begin{array}{c}\mathrm{D}^{1} \\
\min \end{array}$} & \multirow{3}{*}{$\begin{array}{c}\mathrm{Lppt}^{3} \\
\mathrm{~mm} \\
\end{array}$} & \multirow{3}{*}{$\begin{array}{c}\mathrm{Ec} \\
\mathrm{J} \mathrm{m}^{-2}\end{array}$} & \multirow{3}{*}{$\mathrm{N}^{2}$} & \multirow{2}{*}{\multicolumn{5}{|c|}{$\begin{array}{c}\text { PA }(\mathrm{mm}) \\
\text { Cobertura do Solo }\end{array}$}} & \multirow{2}{*}{\multicolumn{5}{|c|}{$\begin{array}{c}\text { PS }\left(\mathrm{Mg} \mathrm{ha}^{-1}\right) \\
\text { Cobertura do Solo }\end{array}$}} \\
\hline & & & & & & & & & & & & & & \\
\hline & & & & & 0 & 20 & 40 & 80 & 100 & 0 & 20 & 40 & 80 & 100 \\
\hline \multirow{10}{*}{60,0} & \multirow{10}{*}{68,0} & \multirow{10}{*}{68,0} & \multirow{10}{*}{1.401} & $1^{\mathrm{o}}$ & 28,1 & 27,3 & 10,4 & 5,4 & 0,9 & 1,9 & 1,3 & 0,7 & 0,0 & 0,0 \\
\hline & & & & $2^{\underline{o}}$ & 44,7 & 41,4 & 23,1 & 16,9 & 3,4 & 2,9 & 1,3 & 0,9 & 0,0 & 0,0 \\
\hline & & & & $3^{\mathrm{o}}$ & 50,1 & 44,5 & 25,6 & 18,9 & 5,4 & 3,5 & 1,3 & 0,7 & 0,1 & 0,0 \\
\hline & & & & $4^{\mathrm{o}}$ & 43,9 & 38,8 & 27,0 & 11,3 & 4,0 & 2,5 & 1,3 & 0,8 & 0,0 & 0,0 \\
\hline & & & & $5^{\mathrm{o}}$ & 66,9 & 48,1 & 32,3 & 19,1 & 7,3 & 3,2 & 1,3 & 0,8 & 0,0 & 0,0 \\
\hline & & & & $6^{\mathrm{o}}$ & 44,2 & 41,1 & 29,5 & 17,2 & 5,6 & 2,2 & 1,3 & 0,8 & 0,0 & 0,0 \\
\hline & & & & $\Sigma$ & 277,9 & 241,1 & 147,9 & 88,6 & 26,5 & 16,1 & 7,9 & 4,8 & 0,1 & 0,0 \\
\hline & & & & $\mathrm{Md}$ & 46,3 & 40,2 & 24,7 & 14,8 & 4,4 & 2,7 & 1,3 & 0,8 & 0,0 & 0,0 \\
\hline & & & & SD & 12,5 & 7,1 & 7,7 & 5,4 & 2,2 & 0,6 & 0,0 & 0,1 & 0,0 & 0,0 \\
\hline & & & & $\mathrm{CV}(\%)$ & 27,0 & 17,7 & 31,1 & 36,7 & 50,5 & 23,3 & 1,0 & 6,6 & 159,5 & 0,0 \\
\hline \multirow{10}{*}{80,0} & \multirow{10}{*}{40,0} & \multirow{10}{*}{53,3} & \multirow{10}{*}{1.122} & $1^{\mathrm{o}}$ & 17,5 & 8,7 & 5,4 & 5,1 & 0,0 & 0,7 & 1,1 & 0,2 & 0,2 & 0,0 \\
\hline & & & & $2^{\mathrm{o}}$ & 32,9 & 15,5 & 13,0 & 5,4 & 0,0 & 2,4 & 1,0 & 0,6 & 0,2 & 0,0 \\
\hline & & & & $3^{\underline{0}}$ & 28,1 & 13,0 & 10,7 & 5,9 & 0,0 & 1,4 & 1,0 & 0,1 & 0,2 & 0,0 \\
\hline & & & & $4^{-}$ & 28,1 & 15,8 & 11,8 & 6,2 & 0,0 & 2,6 & 1,0 & 0,1 & 0,2 & 0,0 \\
\hline & & & & $5^{\circ}$ & 30,6 & 23,1 & 10,7 & 5,4 & 0,0 & 3,0 & 1,0 & 0,3 & 0,2 & 0,0 \\
\hline & & & & $6^{\underline{0}}$ & 32,1 & 30,0 & 15,2 & 7,0 & 0,0 & 3,4 & 1,1 & 0,6 & 0,3 & 0,0 \\
\hline & & & & $\Sigma$ & 169,3 & 106,0 & 66,7 & 34,9 & 0,0 & 13,4 & 6,3 & 1,9 & 1,5 & 0,0 \\
\hline & & & & $\mathrm{Md}$ & 28,2 & 17,7 & 11,1 & 5,8 & 0,0 & 2,2 & 1,1 & 0,3 & 0,2 & 0,0 \\
\hline & & & & SD & 5,6 & 7,7 & 3,3 & 0,7 & 0,0 & 1,0 & 0,0 & 0,3 & 0,0 & 0,0 \\
\hline & & & & $\mathrm{CV}(\%)$ & 20,0 & 43,3 & 29,6 & 12,4 & 0,0 & 45,3 & 3,2 & 81,0 & 18,1 & 0,0 \\
\hline \multirow{10}{*}{100,0} & \multirow{10}{*}{24,0} & \multirow{10}{*}{40,0} & \multirow{10}{*}{841} & $1^{\mathrm{o}}$ & 11,3 & 22,0 & 6,8 & 7,6 & 0,0 & 0,8 & 0,5 & 0,1 & 0,2 & 0,0 \\
\hline & & & & $2^{-}$ & 18,9 & 15,8 & 9,9 & 6,2 & 0,0 & 0,8 & 0,5 & 0,7 & 0,2 & 0,0 \\
\hline & & & & $3^{\mathrm{o}}$ & 23,9 & 15,2 & 13,8 & 6,8 & 0,0 & 0,8 & 0,7 & 0,4 & 0,4 & 0,0 \\
\hline & & & & $4^{-}$ & 25,0 & 17,5 & 10,4 & 7,3 & 1,7 & 1,4 & 0,6 & 0,8 & 0,4 & 0,0 \\
\hline & & & & $5^{\mathrm{o}}$ & 25,9 & 19,1 & 11,8 & 8,5 & 1,7 & 2,3 & 0,3 & 0,4 & 0,2 & 0,0 \\
\hline & & & & $6^{\mathrm{o}}$ & 20,8 & 34,0 & 10,4 & 8,5 & 1,4 & 1,5 & 0,4 & 0,5 & 0,2 & 0,0 \\
\hline & & & & $\Sigma$ & 125,7 & 123,5 & 63,0 & 44,8 & 4,8 & 7,5 & 2,9 & 2,9 & 1,5 & 0,0 \\
\hline & & & & $\mathrm{Md}$ & 21,0 & 20,6 & 10,5 & 7,5 & 0,8 & 1,3 & 0,5 & 0,5 & 0,2 & 0,0 \\
\hline & & & & SD & 5,4 & 7,0 & 2,3 & 0,9 & 0,9 & 0,6 & 0,1 & 0,2 & 0,1 & 0,0 \\
\hline & & & & CV (\%) & 26,0 & 34,1 & 22,1 & 12,1 & 110,4 & 48,0 & 28,9 & 47,6 & 46,8 & 0,0 \\
\hline \multirow{10}{*}{120,0} & & & & $1^{0}$ & 16,9 & 4,5 & 5,6 & 2,0 & 0,0 & 6,3 & 0,6 & 0,4 & 0,2 & 0,0 \\
\hline & & & & $2^{\underline{o}}$ & 20,0 & 8,7 & 7,0 & 2,5 & 0,0 & 3,6 & 1,0 & 0,0 & 0,8 & 0,0 \\
\hline & & & & $3^{-}$ & 22,5 & 7,6 & 5,6 & 2,5 & 0,0 & 2,4 & 0,4 & 0,2 & 0,5 & 0,0 \\
\hline & & & & $4^{-}$ & 19,1 & 10,1 & 8,5 & 4,5 & 3,7 & 2,5 & 0,4 & 0,2 & 0,2 & 0,0 \\
\hline & 140 & 280 & 589 & $5^{\mathrm{o}}$ & 19,7 & 11,0 & 8,5 & 4,5 & 3,4 & 1,5 & 0,4 & 0,2 & 0,2 & 0,0 \\
\hline & 14,0 & 28,0 & 589 & $6^{-0}$ & 19,1 & 9,3 & 7,3 & 3,1 & 4,0 & 1,9 & 0,4 & 0,4 & 0,2 & 0,0 \\
\hline & & & & $\Sigma$ & 117,3 & 51,2 & 42,5 & 19,1 & 11,0 & 18,2 & 3,1 & 1,3 & 2,1 & 0,0 \\
\hline & & & & $\mathrm{Md}$ & 19,6 & 8,5 & 7,1 & 3,2 & 1,8 & 3,0 & 0,5 & 0,2 & 0,4 & 0,0 \\
\hline & & & & $\mathrm{SD}$ & 1,8 & 2,3 & 1,3 & 1,1 & 2,0 & 1,7 & 0,3 & 0,1 & 0,3 & 0,0 \\
\hline & & & & $\mathrm{CV}(\%)$ & 9,3 & 26,8 & 17,9 & 33,7 & 110,0 & 57,5 & 49,7 & 63,9 & 76,9 & 0,0 \\
\hline
\end{tabular}

${ }^{\text {Duração da precipitação; }{ }^{2} \text { evento de }} \overline{\text { precipitação; }} \overline{{ }^{3} \text { lâmina precipitada }}$ 


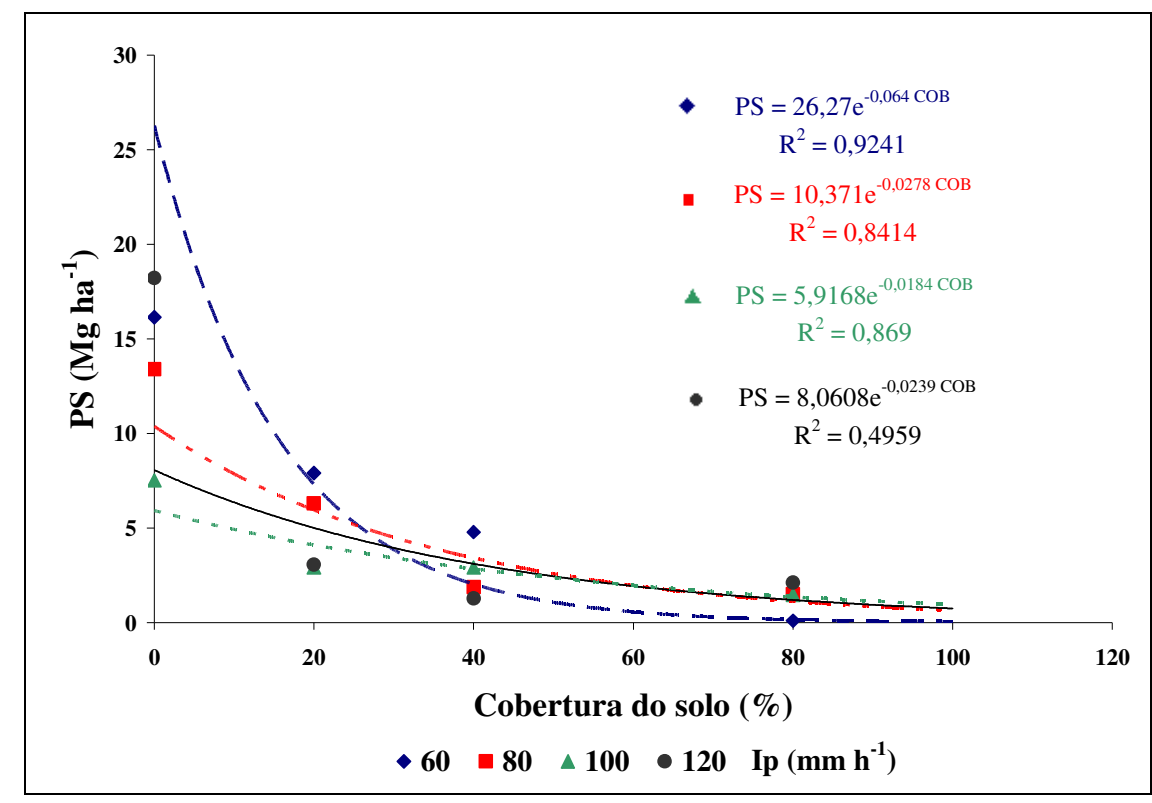

FIGURA 2. Perda de solo acumulada ao final dos seis eventos de chuva em função da porcentagem de cobertura do solo para as diferentes intensidades de precipitação $\left(\mathrm{mm} \mathrm{h}^{-1}\right)$ estudadas.

O efeito da porcentagem de cobertura do solo sobre as perdas de solo acumulada ao final dos seis eventos de chuva, para as diferentes intensidades de precipitação estudadas, é mostrado na Figura 2. Verifica-se que, independentemente da intensidade de precipitação, o acréscimo na porcentagem de cobertura ocasionou acentuada redução na perda de solo. Resultados semelhantes foram obtidos por MANNERING \& MEYER (1963), SWANSON et al. (1965), COGO (1981), LOPES (1984) e AMADO et al. (1989), os quais podem ser explicados pela ação da cobertura do solo em dissipar a energia cinética do impacto direto das gotas da chuva sobre a superfície, diminuindo a desagregação inicial das partículas de solo e, conseqüentemente, a concentração de sedimentos na enxurrada. Além disso, a cobertura do solo representa um obstáculo mecânico ao livre escoamento superficial da água, ocasionando diminuição da velocidade e da capacidade de desagregação e transporte de sedimentos.

Pode-se observar, ainda na Figura 2, que o efeito da cobertura do solo sobre as perdas de solo foi mais pronunciado até $40 \%$ de sua cobertura, concordando com resultados obtidos por COGO (1981), LOPES (1984) e AMADO et al. (1989).

Com relação à energia cinética da precipitação, observa-se tendência de as perdas de solo serem maiores para os menores valores de energia cinética das precipitações no primeiro evento de precipitação e parcelas sem cobertura do solo. Essa observação se deve à incorporação do efeito da duração das precipitações, uma vez que as chuvas mais intensas apresentam durações menores, gerando, conseqüentemente, menor energia cinética da precipitação, sabendo-se que as eqs.(1) e (2) utilizadas para o cálculo da energia cinética são dependentes da lâmina total precipitada.

Analisando conjuntamente o efeito da energia cinética e da cobertura do solo,pode-se observar que, para as parcelas parcialmente cobertas, as maiores perdas de solo ocorrem para os maiores valores de energia cinética, indicando que o potencial erosivo das chuvas intensas (impacto das gotas da chuva sobre o solo) é reduzido pela cobertura do solo, passando, assim, o processo a ser dominado pelo efeito erosivo do escoamento superficial, o qual ocorre por maior período nas chuvas menos intensas, por apresentarem maior duração.

Nas Figuras 3 a 6, são apresentadas as curvas e equações ajustadas referentes aos valores de perda de solo total, em $\mathrm{Mg} \mathrm{ha}^{-1}$, em função da energia cinética total decorrente das sucessivas precipitações e da porcentagem de cobertura do solo. 
Para a intensidade de precipitação de $60 \mathrm{~mm} \mathrm{~h}^{-1}$ (Figura 3), observa-se que a perda de solo diminuiu com o aumento da porcentagem de cobertura. Elevando-se a porcentagem de cobertura de 0 para $80 \%$, verificou-se redução, em média, de $99 \%$ nas perdas de solo. A utilização de apenas $20 \%$ de cobertura resultou em redução de $48 \%$ nas perdas de solo em relação à parcela sem cobertura. Já, com o aumento da energia cinética total de 1.401 para $8.406 \mathrm{~J} \mathrm{~m}^{-2}$, observou-se aumento de oito vezes na perda de solo para a parcela sem cobertura, enquanto na parcela com $80 \%$ de cobertura o mesmo acréscimo gerou aumento de três vezes na perda de solo.

Em relação à intensidade de precipitação de $80 \mathrm{~mm} \mathrm{~h}^{-1}$ (Figura 4), verifica-se, como na intensidade anterior, que a maior perda de solo ocorreu para a parcela sem cobertura, com a tendência de perdas crescentes com o acúmulo da energia cinética. Verifica-se, ainda, redução de $90 \%$ na perda de solo total ao se aumentar a porcentagem de cobertura de $0 \%$ para $80 \%$. Aumentando-se a energia cinética de 1.122 para $6.732 \mathrm{~J} \mathrm{~m}^{-2}$, observou-se aumento de sete vezes no valor da perda de solo total para a parcela com $80 \%$ de cobertura do solo. Nesse caso, observou-se variação muito pequena dos valores de perda de solo entre as parcelas com 40 e $80 \%$ de cobertura.

Analisando as perdas de solo para a intensidade de precipitação de $100 \mathrm{~mm} \mathrm{~h}^{-1}$, apresentada na Figura 5, verifica-se que as maiores perdas de solo também foram obtidas na parcela sem cobertura. $\mathrm{O}$ aumento da porcentagem de cobertura de 0 para $80 \%$ proporcionou redução, em média, de $84 \%$ na perda de solo, enquanto o aumento da energia cinética de 841 para $5.046 \mathrm{Jm}^{-2}$ gerou aumento de dez vezes na perda de solo para a parcela com $80 \%$ de cobertura. As parcelas com 20 e $40 \%$ apresentaram valores médios de perda de solo semelhantes.

Com relação à intensidade de precipitação de $120 \mathrm{~mm} \mathrm{~h}^{-1}$ (Figura 6), verifica-se redução, em média, de $82 \%$ na perda de solo ao se aumentar a porcentagem de cobertura do solo de $0 \%$ para $80 \%$. Aumentando-se a energia cinética de 589 para $3.534 \mathrm{~J} \mathrm{~m}^{-2}$, observou-se aumento de seis e quatro vezes no valor da perda de solo para as parcelas sem cobertura e com $80 \%$ de cobertura, respectivamente. Nota-se, nesse caso, que apenas $20 \%$ de cobertura reduziu a perda de solo a valores próximos das demais porcentagens de cobertura.

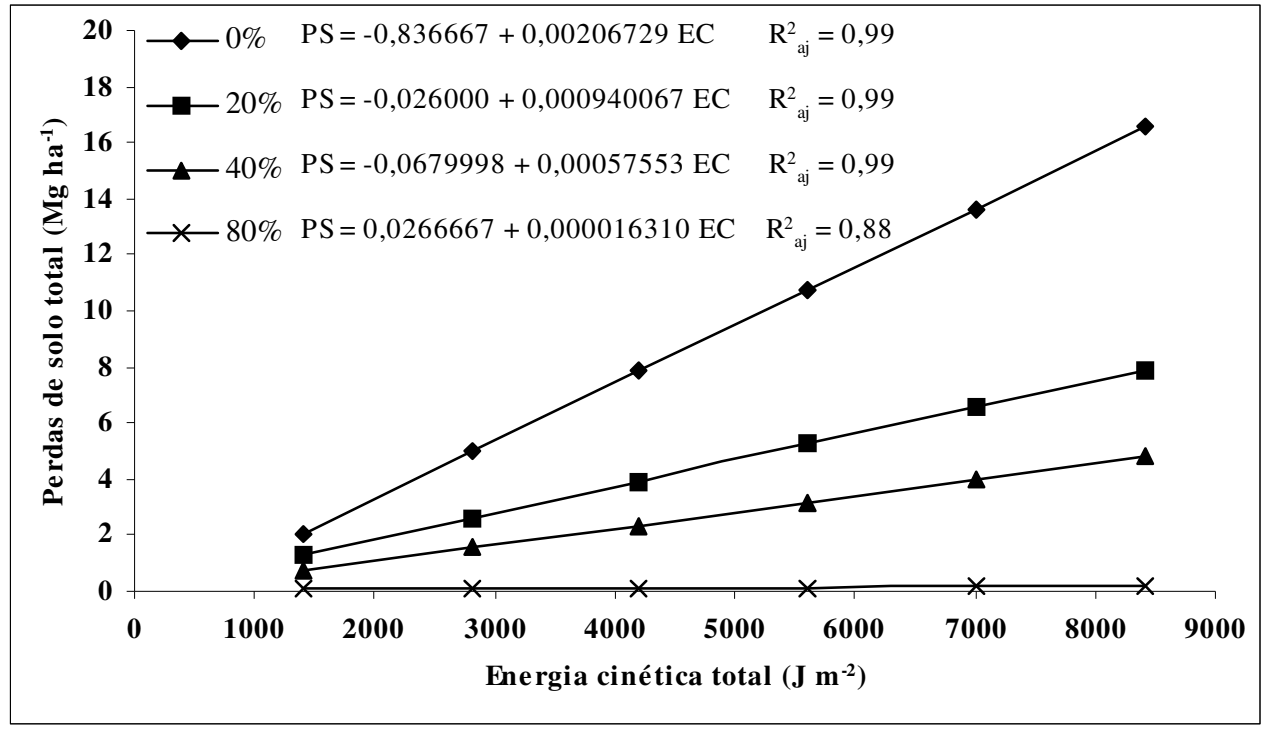

FIGURA 3. Perda de solo total em função da energia cinética total acumulada e porcentagem de cobertura do solo, para a intensidade de precipitação de $60 \mathrm{~mm} \mathrm{~h}^{-1}$. 


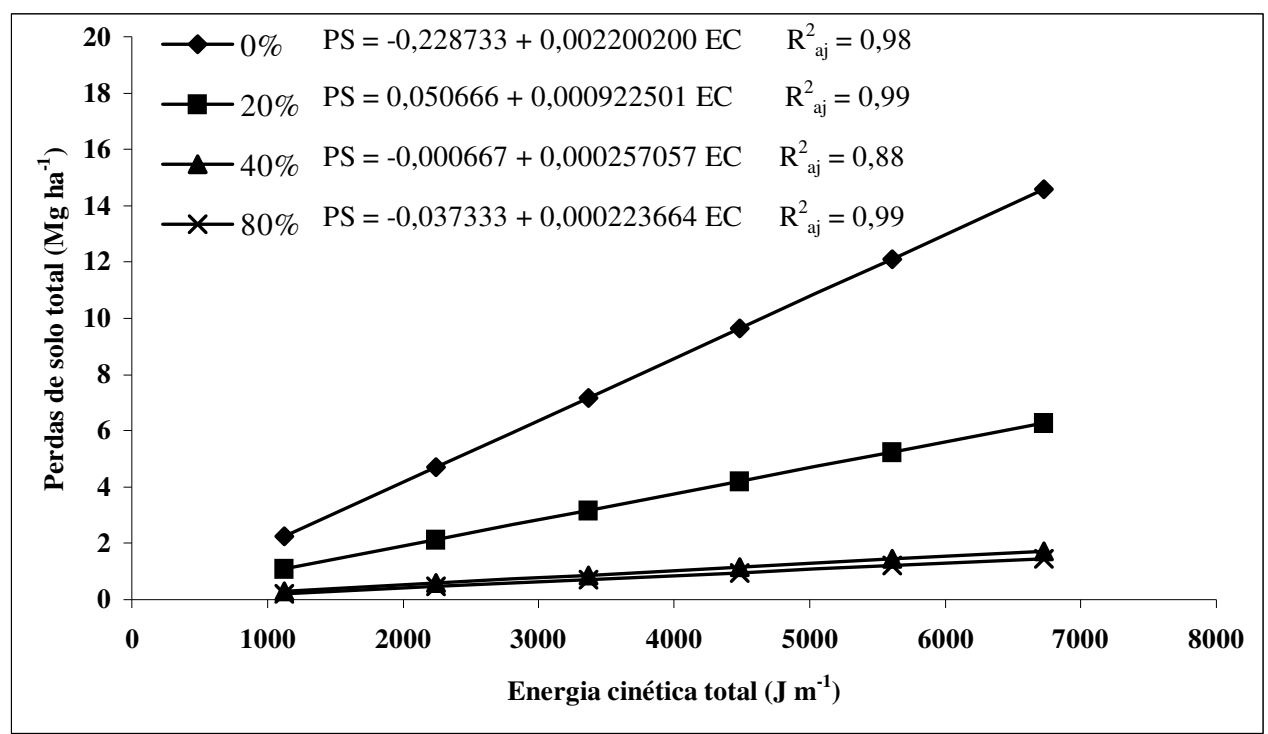

FIGURA 4. Perda de solo total em função da energia cinética total acumulada e porcentagem de cobertura do solo, para a intensidade de precipitação de $80 \mathrm{~mm} \mathrm{~h}^{-1}$.

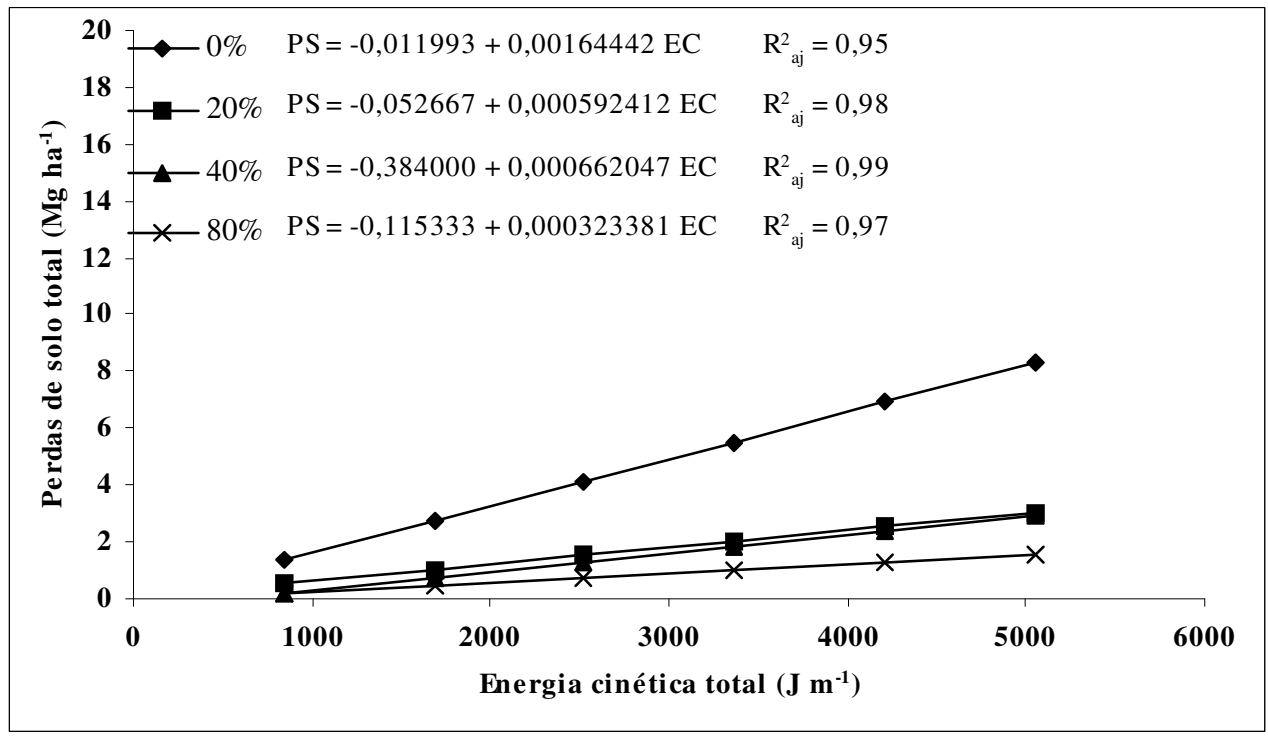

FIGURA 5. Perda de solo total em função da energia cinética total acumulada e porcentagem de cobertura do solo, para a intensidade de precipitação de $100 \mathrm{~mm} \mathrm{~h}^{-1}$. 


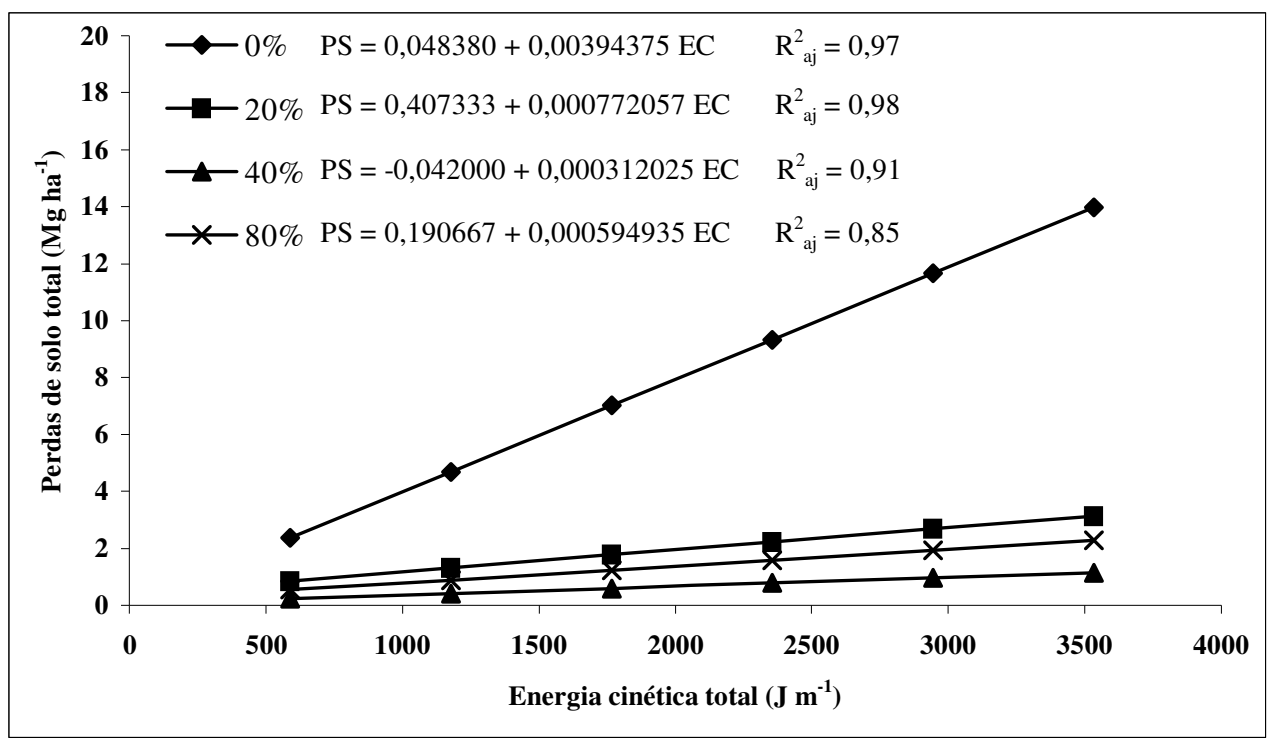

FIGURA 6. Perda de solo total em função da energia cinética total acumulada e porcentagem de cobertura do solo, para a intensidade de precipitação de $120 \mathrm{~mm} \mathrm{~h}^{-1}$.

Pôde-se observar que ocorreu tendência de aumento na perda de solo com a diminuição da intensidade da chuva simulada. Isso ocorreu em virtude de as precipitações menos intensas estarem associadas a maiores durações, proporcionando maiores lâminas de escoamento superficial e, como consequiência, maior perda de solo. YOUNG \& WIERSMA (1973) também verificaram que o escoamento superficial é o principal agente responsável pelo transporte das partículas do solo.

Analisando, ainda, as Figuras 3 a 6, observa-se que a utilização da cobertura do solo, para todas as intensidades de precipitação adotadas, minimizou a ocorrência de escoamento superficial, amortecendo o impacto das gotas de chuva, reduzindo a velocidade e a capacidade de transporte do escoamento superficial e minimizando, dessa forma, as perdas de solo.

\section{CONCLUSÕES}

O acúmulo da energia cinética, resultante das sucessivas aplicações de chuva simulada, acarretou aumento da perda de solo para todas as porcentagens de cobertura do solo.

O aumento da porcentagem de cobertura do solo, para as intensidades de precipitação adotadas, possibilitou diminuição expressiva nas perdas de solo.

A cobertura do solo teve maior influência no controle das perdas de solo do que das perdas de água.

Os maiores valores de perda de solo ocorreram para as menores intensidades de precipitação em decorrência de essas estarem associadas a maiores durações e, conseqüentemente, maiores lâminas precipitadas.

A cobertura do solo apresentou maior influência do que a intensidade de precipitação nas perdas de solo, para a condição de manejo analisada.

O potencial erosivo das chuvas intensas é reduzido pelo aumento da cobertura do solo, passando o processo de erosão a ser dominado pelo efeito erosivo do escoamento superficial, o qual ocorre por maior período nas chuvas menos intensas, por apresentarem maior duração. 


\section{REFERÊNCIAS}

AMADO, T.J.C.; COGO, N.P.; LEVIEN, R. Eficácia relativa do manejo do resíduo cultural de soja na redução das perdas de solo por erosão hídrica. Revista Brasileira de Ciência do Solo, Campinas, v.13, n.2, p.251-7, 1989.

BERTONI, J.; LOMBARDI NETO, F. Conservação do solo. Piracicaba: Livroceres, 1990. 392 p.

BRAIDA, J.A. Relação da erosão entressulcos, com resíduos em cobertura e erosão em sulcos em solo podzólico vermelh- escuro. 1994. 152f. Dissertação (Mestrado em Agronomia) - Universidade Federal do Rio Grande do Sul, Porto Alegre, 1994.

COGO, N.P. Effect of residue cover, tillage-induced roughness, and slope length on erosion and related parameters. 1981. 346 f. Thesis (Ph.D. in Agronomy) - Purdue University, West Lafayette, Indiana, 1981.

FOSTER, G.R. Modeling the erosion process. In: HAAD, C.T. (Ed.) Hydrologic modeling of small watersheds. St. Joseph: ASAE, 1982. cap. 8, p.297-380. (ASAE Monograph, 5)

HERNANI, L.C.; SALTON, J.C.; FABRÍCIO, A.C.; DEDECEK, R.; ALVES JÚNIOR, M. Perdas por erosão e rendimentos de soja e de trigo em diferentes sistemas de preparo de um Latossolo Roxo de Dourados - MS. Revista Brasileira de Ciência do Solo, Campinas, v.21, n.4, p.667-76, 1997.

LOPES, P.R.C. Relações da erosão com tipos e quantidades de resíduos culturais espalhados uniformemente sobre o solo. 1984. 119 f. Dissertação (Mestrado em Recursos Hídricos e Saneamento Ambiental) - Universidade Federal do Rio Grande do Sul, Porto Alegre, 1984.

MANNERING, J.V.; MEYER, L.D. The effect of various rates of surface mulch an infiltration and erosion. Soil Science Society of American Proceeding, Madison, v.27, n.1, p.84-6, 1963.

OWOPUTI, L.O.; STOLTE, W.J. Soil detachment in the physically based soil erosion process: a review. Transactions of the ASAE, St. Joseph, v.38, n.4, p.1099-110, 1995.

PARKER, D.B.; MICHEL, T.G.; SMITH, J.L. Compaction and water velocity effects on soil in shallow flow. Journal of Irrigation and Drainage Engineering, New York, v.121, n.2, p.170-8, 1995.

PINTO, F.A. Chuvas intensas no Estado de Minas Gerais: análises e modelos. 1995. 87 f. Tese (Doutorado em Recursos Hídricos e Ambientais) - Universidade Federal de Viçosa, Viçosa - MG, 1995.

SWANSON, N.P. Rotating-boom rainfall simulator. Transactions of the ASAE, St. Joseph, v.8, n.1, p.71-2, 1965.

SWANSON, N.P.; DEDRICK, A.R.; WEAKLY, H.E.; HAISE, H.R. Evaluation of mulches for watererosion control. Transactions of the ASAE, St. Joseph, v.8, n.3, p.438-40, 1965.

WILDNER, L.P. Efeito da adição de diferentes resíduos orgânicos nas perdas de solo e água em um solo Podzólico Vermelho-Amarelo. 1985. 100 f. Dissertação (Mestrado em Agronomia) - Universidade Federal de Santa Maria, Santa Maria, 1985.

WISCHMEIER, W.H.; SMITH, D.D. Rainfall energy and its relationship to soil loss. Transactions of the American Geophys, Union, v.39, n.2, p.285-91, 1958.

RIBEIRO JÚNIOR, J.I. Análises Estatísticas no SAEG. Viçosa - MG: Editora Folha de Viçosa, 2001. $301 \mathrm{p}$.

YOUNG, R.A.; WIERSMA, J.L. The role of rainfall impact in soil detachment and transport. Water Resources Research, Washington, v.9, n.6, p.1629-36, 1973.

YOUNG, R.A.; BURWELL, R.E. Prediction of runoff and erosion from natural rainfall using a rainfall simulator. Soil Science Society of America Journal, Madison, v.36, n.5, p.827-30, 1972. 